\title{
The Insight Diversification Characteristic of Real Estate Security in Capital Market under Sharpe's Asset Class Factor Model: The Case of Thai Property Funds
}

\author{
Aekkachai Nittayakasetwat and Jiroj Buranasiri
}

\begin{abstract}
This study investigates Thai property funds' in-depth diversification ability during 2003 and 2011 by applying Sharpe asset allocation method. The equally weighted property fund portfolio is built and replicated by a portfolio built from 12 asset classes including government's short term bills, government's intermediate-term bonds, government's long-term bonds, corporate bonds, property sector stock Index, large capitalization value socks, large capitalization growth stocks, medium-capitalization stocks, small-capitalization stocks, non-Thai market bond index, developed market stock index and emerging market stock. The result shows that Thai property funds' behavior is exposed to corporate bond $(60 \%)$, medium-capitalization stock $(21 \%)$ and small-capitalization stock $(10 \%)$. However, the analysis also indicates that the equally weighted property fund portfolio is made up of style component by only $47 \%$. There exists a unique characteristic of property funds which could not be found from other asset classes. The existence of property funds allows investors to further eliminate diversifiable risk in their portfolio.
\end{abstract}

Index Terms - Equally weighted property fund portfolio, large-capitalization value socks, large-capitalization growth stocks, medium-capitalization stocks.

\section{INTRODUCTION}

The first property fund in Thailand is found in 2003. The main objectives of the creation are to mobilize funds for property developers and to provide chance for small investors to invest their money in real properties. The newness of the property fund market, however, brings about the doubt on the characteristics of the return and benefit of risk diversification from property fund investment. Property funds' rental contracts make their revenue quite predictable but the stock market trading could make the return on the funds' investment units fluctuate with the market. The understanding on property funds' returnin relation to other assets will lead to the understanding on their risk diversification characteristic. Nevertheless, it is hard to find the studies on Thai property funds. Most studies were done on common stocks' returns.

This study uses Sharpe Asset Class Factor Model proposed in [1] to analyze property funds' return characteristics. In

Manuscript received June 3, 2014; revised August 27, 2014. This work was supported in part by National Institute of Development and Administration.

Aekkachai Nittayakasetwat is with NIDA Business School, National Institute of Development, Thailand (e-mail: bbawtt@ hotmail.com).

Jiroj Buranasiri is with the Department of Business Administration, Faculty of Social Science, Srinakharinwirot Unisversity, Thailand (e-mail: jirojresearch@gmail.com). general, this model will disclose the similarity between property funds and other asset classes. This study is very useful for helping investors to understand the nature of property funds' return in relation to other asset classes and their risk diversification ability. Consequently, investors will be able to improve their asset allocation and build more efficient investment portfolio. In addition, the findings add more evidences for academic researches on the performance of real estate security investment.

\section{PRIOR LITERATURES}

Thai property funds are less flexible than real estate investment trusts (REITs) concerning the maximum debt leverage at $10 \%$ of their assets and the maximum unit holding proportion at $33.33 \%$. However, they are similar to REITs in other countries at least three aspects. First, the funds sell their investment units to public and these units will be trading on the exchange later. Second, the money received from the units selling is used for the purchase of real properties which will be rented for the funds' future revenue. Last, most of the funds' income must be paid back to investors. Thai property funds are required to pay at least $90 \%$ of their' profit to the unit holders to receive tax exemption. Since there are few researches done on Thai property funds, the review on REITs, therefore, helps in understanding the nature of property funds.

Many studies find supportive evidences that REITs provide diversification benefit to investors. Commonly, investors could diversify their risk when they invest their money in different type of assets as mentioned in [2]. In other words, if REITs are unique from other assets or have mixed characteristics of many assets, adding REITs into investors' portfolios will lower the portfolios' risk.

For the researches on REITs' uniqueness, Lee and Chiang [3] and Chan, Erickson, and Wang [4] claim that though REITs and common stocks are trading on the exchange, their performances are different. Mori and Ziobrowski [5] conclude that REITs' return behave different from other assets' return because REITs' characteristics are distinctive. Specifically, Downs [6] argues that the institutional ownership structure is the important factor which influence REIT returns.

For the mixed characteristics of different assets in REITs, several prior studies report that, to some extent, REIT behaves the same as bond, common stock, and or real estate.

In case of bond-alike view, many researches were done on the interest rate sensitivity aspects of REITs because bonds are highly sensitive to interest rate and both REITs and 
bonds' cash flows are highly predictable. Many of them show supportive evidence, for example, Buranasiri and Nittayakasetwat [7] reportthe existence of the relationship between REIT return and long-term corporate bond return.

For the view that REIT investment is similar to common stock investment, the reason is rooted from the facts that REIT investors receive REITs' residual income the same as common stock investors and both REITs and common stocks are trading on the exchange. Li and Wang [8] find that REIT and stock market are not segmented. Liang [9] concludes that REITs are similar to income stocks. Cotter and Stevenson [10] discover the increasing relationship between REITs and common stocks while Su, Huang, and Pai [11] find the strong relationship of REITs and common stocks occurring during low volatility period.

For real estate-alike characteristic, because incomes of REITs are from their investment in real properties and most of the incomes are allocated back to REIT investors, a group of researchers have examined whether there is the relation between the return of REIT investment and the return of real estate investment. Boudry, Coulson, Kallberg, and Liu [12] uncover the existence of the long-run relation between REIT and real estate investment return so do Hoesli and Oikarinen [13]. Nevertheless, many studies, such as the study by Nneji, Brooks, and Ward [14], indicate that REITreturn is influenced by stock market more than property market.

Though these studies are very interesting, none of them provides solution to explain the diversification characteristics of the real estate securities in relation to many securities trading in capital market together. Sharpe's technique is found to be the method which could provide the solution. It could explain the characteristic of the real estate securities' return by decomposing REITs into different asset classes available in financial market. Therefore, this paper uses Sharpe's technique to explore the characteristics of Thai property funds.

\section{MethodOLOGY}

\section{A. Data}

To apply Sharpe (1992) technique, this study changes some asset classes from the original model but keeps the core concept of using mutually exhaustive and exclusive asset classes in the model. The followings are the monthly returns of equally weighted property fund portfolio and of 12 classes used for this paper (see Table I):

TABLE I: 12 CLASSES AND MONTHLy RETURNS OF EQUALLY WEIGHTED PROPERTY FUND PORTFOLIO

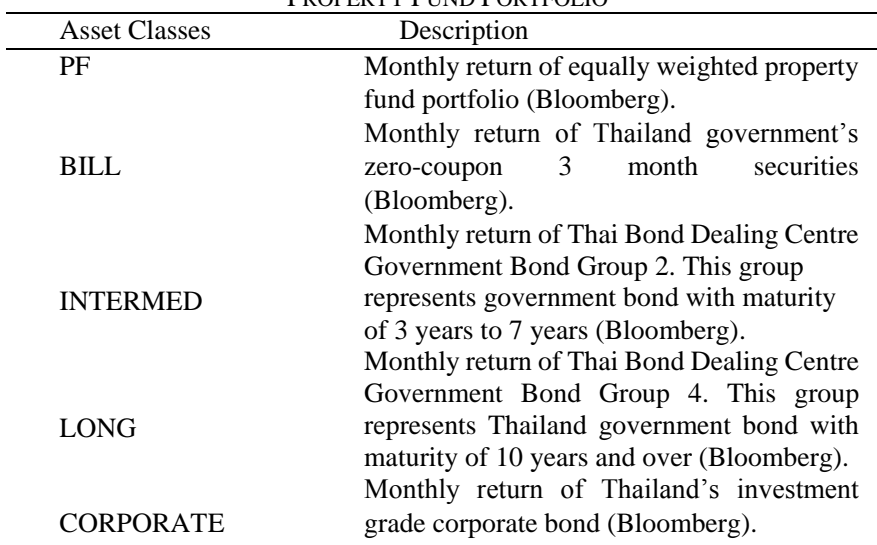

SETPROP

M_STOCK

DEVELOPED_MKT market. This study uses MSCI world developed market index (Bloomberg) as proxy.

Monthly return of stocks in emerging market. This study uses VANGUARD emerging market stock index (Bloomberg) as proxy.

This research collects time series data of property funds listed on the Stock Exchange of Thailand and 12 asset classes during 2003, when the first property fund was introduced, to the end of 2011 from Bloomberg database.

\section{B. Procedure}

The asset class factor model from Sharpe (1992) which was used to find out the investment style of different mutual funds in U.S. is replicated on Thai property fund. Generally, a portfolio is built from different 12 asset classes to replicate the equally weighted property fund portfolio. The weights for each asset classes, then, show the characteristics of Thai property fund. To be specific, equally weighted property fund portfolio will be imitated by the portfolio created from 12 asset classes under the asset class factor model in the below equations:

$$
R_{i}=\left(b_{i 1} F_{1}+b_{i 2} F_{2}+\ldots b_{i n} F_{n}\right)+e_{i}
$$

or

$$
e_{i}=R_{i}-\left(b_{i 1} F_{1}+b_{i 2} F_{2}+\ldots b_{i n} F_{n}\right)
$$

where $R_{i}$ is return on asset $i$

$F_{1}$ is value of factor 1

$F_{2}$ is value of factor 2

$F_{n}$ is value of factor $n$

$b_{i 1}$ through $b i_{1}$ are the sensitivities of $R_{i}$ to factor $F_{1}$ 
through $F_{n}$

$e_{i}$ is non-factor component of return $R_{i}$

The terms in the bracket in equation 1 is the return contribution from style of the fund and $e_{i}$ is due to the selection. The value in equation 2 is the difference between the return of the equally weighted property fund portfolio and the return of portfolio built from 12 asset classes.

To investigate the attributes of property funds, this study run regression under 3 conditions: First, the portfolio is built according to the regression model which best fits the portfolio of property fund. Each asset class's beta coefficient represents its weight (in percent) in the portfolio. Second, the portfolio is built through the regression model in the same way as method 1, but the total weight must be equal to $100 \%$. Third, the portfolio is built under quadratic equation and each beta is restricted to be in the range of $0 \%$ to $100 \%$. The restriction is subjected to the fact that net short sale position is not allowed for most Thai investors.

The target portfolio which is built from the 12 asset classes is the portfolio which has lowest variance of $e_{i}$, tracking error which is the difference between the return on the portfolio of equally weighted property funds and the return of the target portfolio.

The portfolio created from the 12 asset classes is the passive portfolio with the same style as the portfolio of property funds. The exposure of portfolio of property funds to each of the 12 asset classes is, hence, determined by the weight of asset classes in the created portfolio. Then, $\mathrm{R}$-square, $R^{2}$, is determined with the following equation:

$$
R^{2}=1-\frac{\sum_{i}^{n}\left(R_{i}-R_{p i}\right)^{2}}{\sum_{i}^{n}\left(R_{i}-E\left(R_{i}\right)\right)^{2}}
$$

where $R_{p i}$ is the monthly return of the portfolio built from 12 asset classes.

The R-square represents the portion of variance of $R_{i}$ which is explained by asset classes and 1 minus R-square, thus, indicates the unexplained portion.

\section{RESUlt OF STUdY}

\section{A. Descriptive Statistics}

Table II indicates that the developed market stock class (DEVELOPED_MKT) rewards lowest mean monthly return at $1.26 \%$ and the small-capitalization stock class (S_STOCK) gives the highest mean monthly return at $2.31 \%$. The standard deviation of investment grade corporate bond's monthly return (CORPORATE) is the lowest at $0.83 \%$ and the standard deviation of monthly return of the property sector stocks (SETPROP) is highest at $8.95 \%$. Nevertheless, when the mean monthly returns of these asset classes are measured in relation to their standard deviation, the investment grade corporate bond class (CORPORATE) provides highest return in relation to standard deviation while the property sector stock provides lowest return in relation to standard deviation (SETPROP).

In particular, the equally weighted portfolio of property funds $(\mathrm{PF})$ has mean monthly return of $0.59 \%$, standard deviation of $2.83 \%$ and mean monthly return in relation to standard deviation of 0.21 . For the remainders, their mean monthly returns, standard deviations, and mean monthly return in relation to standard deviation are as follow: Thailand government's zero-coupon 3 month securities (BILL: $1.58 \%, 11.74 \%, 0.13$ ), Thailand government's intermediate-term bonds (INTERMED: $0.41 \%, 2.44 \%, 0.17$ ), Thailand government's long-term bonds (LONG: 0.60\%, $3.49 \%$, 0.17), investment grade corporate bond (CORPORATE: $0.40 \%, 0.83 \%, 0.48$ ), property sector Stock (SETPROP: $0.48 \%, 8.95 \%, 0.05$ ), large-capitalization value stocks (V_STOCK: 1.26\%, 7.54\%, 0.17), large-capitalization growth stocks (G_STOCK:1.41\%, 7.41\%, 0.20), medium-capitalization stocks (M_STOCK: 0.63\%, 5.21\%, 0.12), small-capitalization stocks (S_STOCK: $2.31 \%, 5.66 \%$, 0.41 ), non-Thai bonds (NONTHAI_BOND: $0.52 \%, 1.80 \%$, 0.29), developed market stocks (DEVELOPED_MKT: $0.33 \%, \quad 4.87 \%, 0.07)$, and emerging-market stocks (EMERGING_MKT: $1.26 \%, 7.41 \%, 0.17)$.

TABLE II: MEAN, STANDARD DEVIATION, AND MEAN IN RELATION TO STANDARD DEVIATION OF THE EQUALLY WEIGHTED PROPERTY FUND PORTFOLIO’S MONTHLY RETURN AND 12 ASSET ClASSES' MONTHLY RETURNS

\begin{tabular}{lccc}
\hline Variables & $\begin{array}{c}\text { Mean } \\
(\%)\end{array}$ & $\begin{array}{c}\text { Standard } \\
\text { Deviation }(\%)\end{array}$ & $\begin{array}{c}\text { Mean/Standard } \\
\text { deviation }\end{array}$ \\
\hline PF & 0.59 & 2.83 & 0.21 \\
BILL & 1.58 & 11.74 & 0.13 \\
INTERMED & 0.41 & 2.44 & 0.17 \\
LONG & 0.60 & 3.49 & 0.17 \\
CORPORATE & 0.40 & 0.83 & 0.48 \\
SETPROP & 0.48 & 8.95 & 0.05 \\
V_STOCK & 1.26 & 7.54 & 0.17 \\
G_STOCK & 1.41 & 7.14 & 0.20 \\
M_STOCK & 0.63 & 5.21 & 0.12 \\
S_STOCK & 2.31 & 5.66 & 0.41 \\
NONTHAI_BOND & 0.52 & 1.80 & 0.29 \\
DEVELOPED_MKT & 0.33 & 4.87 & 0.07 \\
EMERGING_MKT & 1.26 & 7.41 & 0.17 \\
\hline
\end{tabular}

Table III shows the potential of the use of property funds to diversify investors' risk. The correlation coefficients between the portfolio of property funds' monthly return (PF) and all 12 asset classes are not high. Most correlation coefficients between the property funds' monthly return and the other asset classes are positive and statistically significant. Only the coefficients between the portfolio of property funds' monthly return and all Thai bond asset classes' monthly returns (BILL, INTERMED, LONG, and CORPORATE) are negative and not statistically significant.

The correlation coefficients among pairs of asset classes are mixed of both negative and positive. Besides most of them are not high, except the pair of monthly return of emerging market stocks (EMERGING_MKT) and developed market stocks (DEVELOPED_MKT), large-capitalization value stocks (V_STOCK) and large-capitalization growth stocks (G_STOCK), property sector stocks (SETPROP) and medium-capitalization stock (M_STOCK), Thailand government's intermediate-term bonds (INTERMED) and investment grade corporate bonds (CORPORATE), property sector stocks (SETPROP) and large-capitalization value stocks (V_STOCK), and large-capitalization value stock (V_STOCK) and medium-capitalization stock (M_STOCK) at $0.90,0.894,0.89,0.882,0.85$, and 0.826 consecutively. 


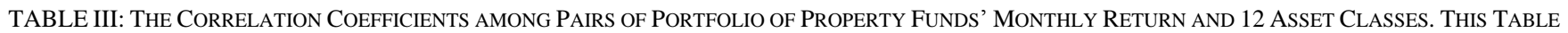
SHOWS THE CORRELATION OF PORTFOLIO OF PROPERTY FundS' MEAN MONTHLY RETURN AND 12 ASSET CLASSES' MONTHLY RETURNS

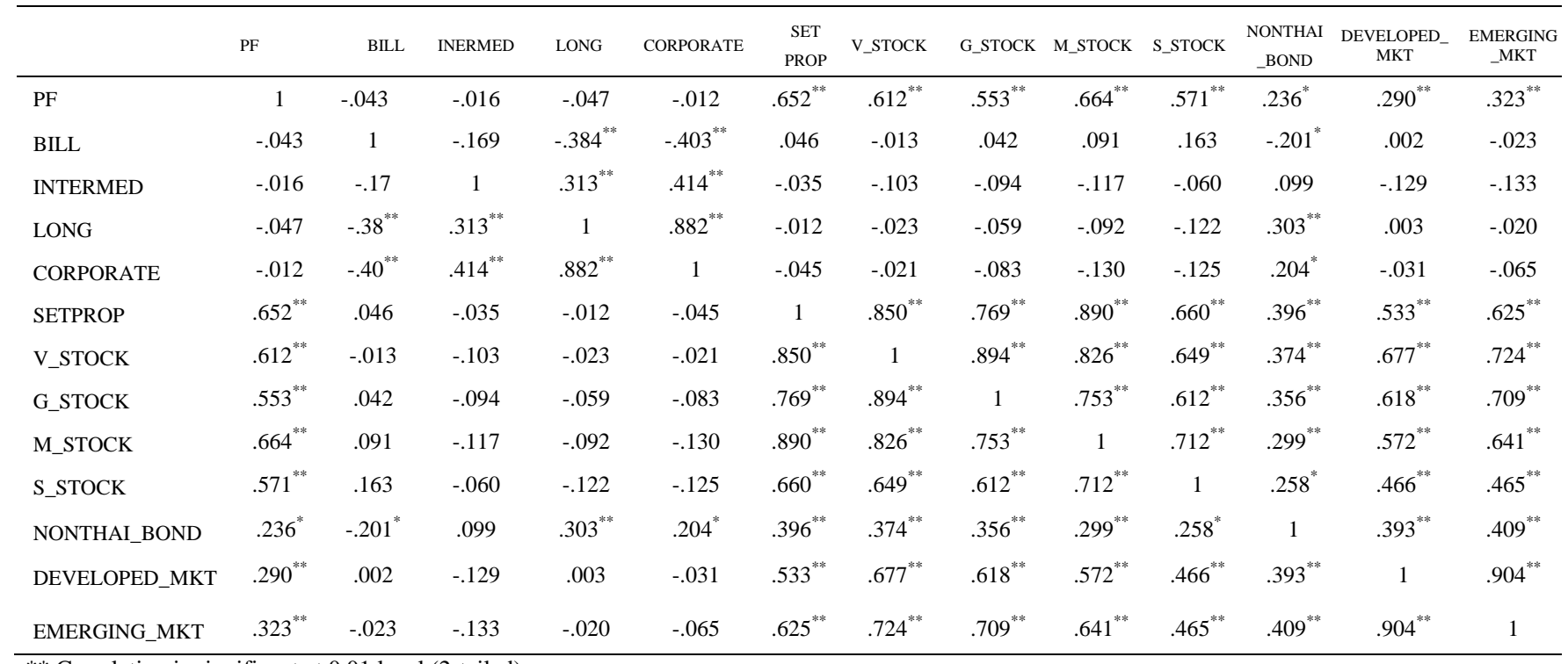

** Correlation is significant at 0.01 level (2-tailed)

* Correlation is significant at 0.05 level (2-tailed)

\section{B. Empirical Findings}

For the insight of property funds' diversification characteristics, the asset class factor model in Sharpe (1992) is used and the component of investment style is analyzed. The weight components of the best built portfolio replicating equally weight property fund portfolio in Fig. 1 point out that property funds, in average, expose to investment grade corporate bond asset class most at $59.91 \%$ weight, followed by medium-capitalization stock asset class at $21.36 \%$, small-capitalization stock asset class at $9.51 \%$, and property sector stock class at $4.94 \%$.The remainders of asset classes together contribute only $4.28 \%$ The high weight on bond might be because bonds and property funds are not riskless assets and both of them have highly predictable cash flows Surprisingly, the exposure to property sector stock asset class is very small though both property fund and property sector stock should share some fundamentals on real property.

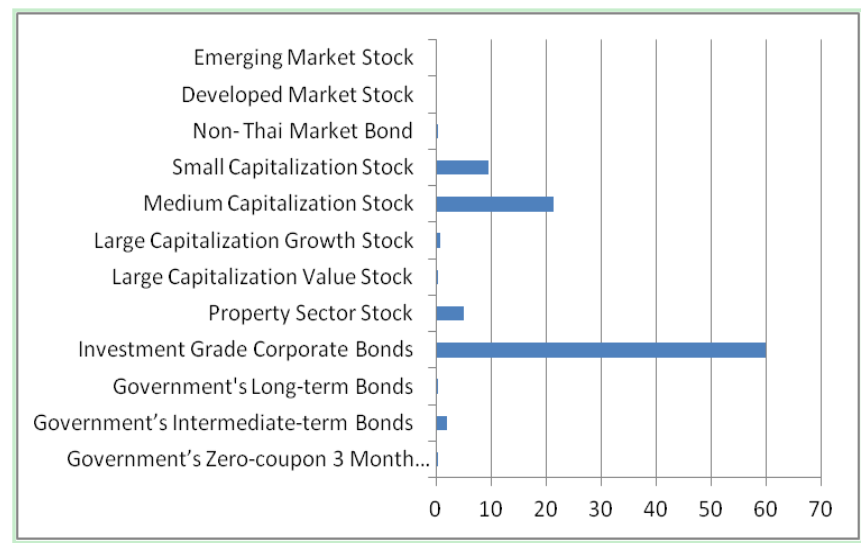

Fig. 1. Average Thailand property funds' style during 2003 to 2011.

The further analysis which breakdowns the return performance of the equally weighted property fund portfolio into style and selection components in Fig. 2 indicates that the behavior of Thailand's property funds is composed up of style by only $46.6 \%$ (R-square value) and selection by up to $53.4 \%$. In other words, the 12 asset classes could explain average property funds by less than half of their behavior.
The high selection part proves that property funds are unique from other asset classes and, hence, is worth to add on investors' portfolio to lower the diversifiable risk.

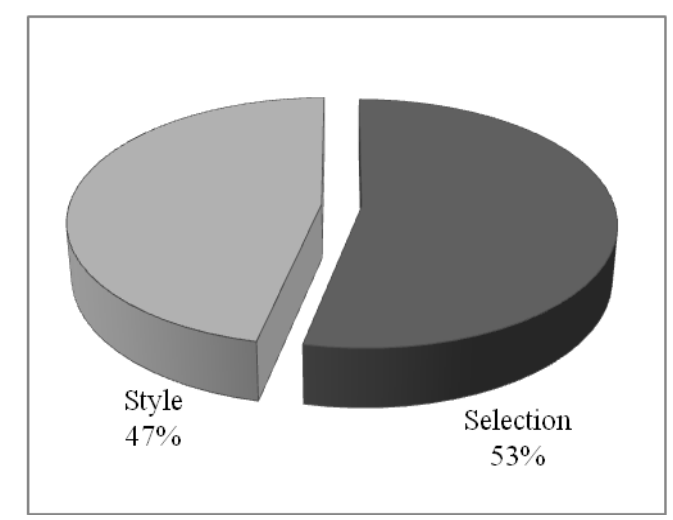

Fig. 2. Average Thailand property funds' style and selection break-down during 2003 to 2011.

\section{CONCLUding REMARKS}

The study examines behavior of Thai property funds against other 12 asset classes. The diversification property is clearly found. Thai property funds and other asset classes are not highly correlated. This primary investigation indicates that by adding property funds into investors' portfolio, the portfolio risk will be reduced. The negative correlation is found on the pair between property funds and Thai local bond asset classes but not statistically significant. The further analysis is done by using Sharpe (1992)'s asset class factor model and the results reveal that the part of property fund return's performance, so called style component, is similar to the mix of four main important asset classes: investment grade corporate bond asset class, medium-capitalization stock asset class, small-capitalization stock asset class, and property sector stock asset class. However, the larger component of the return's performance, so called selection portion, could not be explained by the holding any of the 12 tested asset classes. This part implies the existence of property funds' own unique return behavior. In other words, 
property funds are the real new risk diversification tools. By adding property funds into investors' portfolios, investors do receive additional risk diversification benefit.

\section{REFERENCES}

[1] W. F. Sharpe, "Asset allocation," The Journal of Portfolio Management, vol. 18, no. 2, pp. 7-19, 1992.

[2] A. J Keown, J. D. Martin, J. W. Petty, and D. F. Scott, Financial Management: Principles and Applications, 10th ed. Prentice Hall Englewood Cliffs, NJ, 2002, ch. 6, pp. 192-193.

[3] M. Lee and K. Chiang, "Long-run price behavior of equity REITs: become more like common stocks after the early 1990s?" Journal of Property Investment \& Finance, vol. 28, no. 6, pp. 454-465, 2010.

[4] S. H. Chan, J. Erickson, and K. Wang, Real Estate Investment Trusts: STRUCTURE, Performance, and Investment Opportunities, Oxford University Press, 2003, ch. 1, pp. 6-7.

[5] M. Mori and A. J. Ziobrowski, "Performance of pairs trading strategy in the U.S. REIT market," Real Estate Economics, vol. 39, no. 3, pp. 409-428. 2011.

[6] D. H. Downs, "The value in targeting institutional investors: Evidence from the five-or-fewer rule change." Real Estate Economics, vol. 26, no. 4 , pp. $613-649,1998$.

[7] J. Buranasiri and A. Nittayakasetwat, "Real estate investment performance: the test of the impact of additional interest rate information from CIR model," International Journal of Business and Social Science, special issue, vol. 3, no. 12, pp. 134-143, June 2012.

[8] Y. Li and K. Wang, "The predictability of REIT returns and market segmentation," Journal of Real Estate Research, vol. 10, no. 4, pp. 471-482, 1995.

[9] Y. Liang, "REIT correlation with stock indices," Prudential Real Estate Investors Research Notes, pp. 1-3, 2000.

[10] J. Cotter and S. Stevenson. "Multivariate modeling of daily REIT volatility," Journal of Real Estate Finance and Economics, vol. 32, no. 3, pp. 305-325, 2006.
[11] H. Su, C. Huang, and T. Pai, "The hybrid characteristic of REIT returns: evidence from Japanese and U.S. States markets," Journal of Real Estate Literature, vol. 18, no. 1, pp. 77-98, 2010.

[12] W. I. Boundry, N. E. Coulson, J. G. Kallberg, and C. H. Liu, “On the hybrid nature of REITs," Journal of Real Estate Finance and Economics, vol. 44, no. 1, pp. 230-249, 2012.

[13] M. Hoesli and E. Oikarinen, "Are REITs real estate? Evidence from international sector level data," Journal of International Money and Finance, vol. 31, no. 7, pp. 1823-1850, 2012.

[14] O. Nneji, C. Brooks, and C. Ward, "Commercial real estate and equity market bubbles: are they contagious to REITs," Urban Study, vol. 50, no. 12 , pp. 2496-2516, 2013.

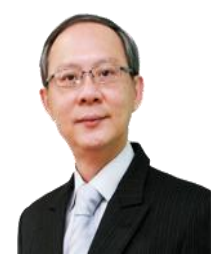

Aekkachai Nittayakasetwat is an associate professor at NIDA Business School, National Institute of Development Administration (NIDA), Thailand. He is certified as a financial risk manager from FRM® Global Association of Risk Professionals (GARP) and holds a Ph.D. degree in finance from University of Mississippi, USA. He was the dean of NIDA Business School and the director of the Flexible MBA Program of National Institute of Development Administration and currently is the director of several companies. His research interests are in finance, especially in real estate investment, corporate social responsibility, and corporate governance.

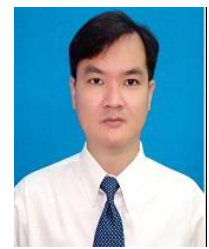

Jiroj Buranasiri is a lecturer at the Department of Business Administration, Faculty of Science, Srinakharinwirot University, Thailand. He is a CFA charter holder. He holds a Ph.D. degree in finance from National Institute of Development Administration (NIDA) and Ms. degree in finance from University of Colorado. His research interests are in property funds, real estate investment trust, fixed income securities, alternative investment, and corporate finance. 